\title{
Memorias emergentes: las consecuencias inesperadas de la Ley de Justicia y Paz en Colombia (2005-2011)
}

\author{
Emerging Memories: The Unintended Consequences of the 2005 \\ Justice and Peace Law in Colombia (2005-2011) \\ As consequências inesperadas da Lei de Justiça e Paz na Colômbia \\ (2005-2011)
}

\section{JuAn PABlo Vera Lugo*}

FECHA DE RECEPCIÓN: 17 DE AGOSTO DE 2014. FeCHA DE ACEPTACIÓN: 3 DE DICIEMBRE de 2014

Doi: dx.doi.org/10.12804/esj17.02.2015.01

Para citar este artículo: Vera Lugo, J. P., (2015). Memorias emergentes: las consecuencias inesperadas de la Ley de Justicia y Paz en Colombia (2005-2011). Estudios Socio-Jurídicos, 17(2), 13-44. Doi: dx.doi.org/10.12804/esj 17.02.2015.01

\section{RESUMEN}

Este artículo explora las consecuencias inesperadas de la Ley de Justicia y Paz promulgada en el año 2005 para desmovilizar los grupos paramilitares y reincorporarlos a la sociedad. Argumenta que si bien esta hizo énfasis en los procesos de desarme, desmovilización y reinserción de los combatientes a la sociedad, la incorporación de los principios de verdad, justicia y reparación a la norma transformó el marco interpretativo sobre el conflicto en Colombia y las formas de construcción histórica tradicional. Con ello, dio herramientas importantes de reorganización a grupos sociales y de víctimas. Teniendo en cuenta que las instituciones y organizaciones estudiadas en el artículo nacieron como reacción o resultado de la implementación de esta ley, se argumenta que la externalidad del derecho produjo consecuencias políticas y culturales positivas, no previstas por el legislador. Para estudiar este proceso de incorporación y apropiación de mecanismos de justicia transicional en ámbitos institucionales y organizativos, este texto se enfoca en los diferentes actores, grupos sociales, expertos, funcionarios, líderes sociales, etc., que negocian los términos en los cuales el pasado, el presente y el futuro pueden ser pensados, representados y reinterpretados bajo este nuevo marco.

Palabras clave: Justicia transicional, memoria, vida social del derecho, institucionalización de la memoria.

* Magíster en antropología, Rutgers University. Profesor investigador del Departamento de Antropología, Pontificia Universidad Javeriana. Este artículo es producto del proyecto de investigación titulado "Políticas y tecnologías de la memoria: lecturas oficiales y no oficiales de la memoria en medio del conflicto colombiano" (2008-2010). Correo electrónico: veraj@javeriana.edu.co 


\section{ABSTRACT}

The article explores the unintended consequences of the 2005 Justice and Peace Law enacted by Colombian congress in order to reincorporate paramilitary groups into society. The article argues that although the law emphasizes in DDR (Disarm, Demobilization and Reincorporation) mechanisms, the incorporation of transactional justice principles (truth, justice and redress) into the statute transformed the interpretative frame of Colombian conflict by state and non-state actors as well as the traditional mechanisms of historical account. The incorporation of these principles also became central tools for the mobilization, empowerment and re-legitimation of social and victim's organizations. The article investigates the political and cultural consequences of this law by studying the work of governmental and nongovernmental institutions created in Colombia as a result and as a reaction of the Law. In order to explore the process of appropriation and incorporation of transitional justice mechanisms in these institutional and organizational contexts, the article focuses on experts, civil servants and social activist that challenge the normative purpose of the Law and negotiate the terms in which the past, the present and the future can be thought, represented and interpreted under transitional justice as a new horizon of meaning.

Key words: Transitional Justice, memory, social life of law, institutionalization of memory, unintended consequence of the law.

\section{RESUMO}

Este artigo explora as consequências inesperadas da Lei de Justiça e Paz promulgada no ano 2005 para desmobilizar os grupos paramilitares e reincorpora-los à sociedade. Argumenta que se bem esta lei fez ênfase nos processos de Desarme, Desmobilização e Reinserção dos combatentes à sociedade, a incorporação dos princípios de verdade, justiça e reparação à norma transformou o marco interpretativo sobre o conflito na Colômbia e as formas de construção histórica tradicional. Com isto, deu ferramentas importantes a organizações sociais e de vítimas para sua reorganização. Tendo em conta que as instituições e organizações estudadas no artigo nasceram como resultado da implementação ou como reação a esta lei, argumenta-se que a externalidade do direito levou consequências políticas e culturais positivas não previstas pelo legislador. Para estudar este processo de incorporação e apropriação de mecanismos de justiça transicional em âmbitos institucionais e organizativos, o artigo foca-se nos diferentes atores, grupos sociais, expertos, funcionários e líderes sociais, etc., que negociam os termos nos quais o passado, o presente e o futuro podem ser pensados, representados e reinterpretados sob este novo marco.

Palavras-chave: Justiça transicional, memória, vida social do direito, institucionalização da memória. 
Este artículo explora la vida social de un dispositivo jurídico-político como lo es la ley de Justicia y Paz (Ley 975 de 2005), desde su promulgación en el año 2005 hasta enero de 2011, cuando se aprobó la Ley de Víctimas y Restitución de Tierras, ${ }^{1}$ y analiza la emergencia de los mecanismos de la justicia transicional en Colombia, particularmente los relacionados con la exploración de las tecnologías de la memoria, ${ }^{2}$ sus usos, apropiaciones y resistencias por organizaciones sociales e instituciones gubernamentales. ${ }^{3}$ Dicha apropiación y resistencia social e institucional termina legitimando las luchas de organizaciones sociales y de víctimas, y al mismo tiempo brinda elementos para la relegitimación del estado colombiano, sin que este tenga que superar los problemas estructurales asociados tradicionalmente a las causas del conflicto. ${ }^{4}$ De esta manera, el texto propone, primero, una lectura de los efectos inesperados de la Ley Justicia y Paz, problematizando el derecho a la verdad y la memoria como dispositivos de la justicia transicional apropiados por instituciones públicas y organizaciones sociales, ${ }^{5} \mathrm{y}$

1 Hago uso del concepto de vida social del derecho empleado por Lila Abu-Lughod (2011) para referirse a cómo los derechos de las mujeres en Egipto y Palestina, apropiados del Derecho Internacional de los Derechos Humanos pueden ser localizados en lugares, espacios y agentes sociales específicos.

2 Retomo el concepto de tecnologías de memoria de Marita Sturken (1997) quien indica que la memoria cultural es producida por medio de objetos, imágenes y representaciones. Esta no reside pasivamente en un espacio o tiempo específicos, sino que es activamente producida y compartida, y, además, se le atribuyen nuevos sentidos. La memoria es producida por medio de múltiples dispositivos: arte público, memoriales, docudramas, televisión, fotografía, publicidad, libros, informes, comisiones de la verdad, espacio público, etc. (Sturken, 1997, p. 10). Allen Feldman (2003) también hace alusión a este concepto, indicando que esta funciona como tecnología política (Feldman 2003, p. 61). Aquí uso el concepto en ambos sentidos al final, particularmente el último.

3 La justicia transicional va más allá del problema de la justicia. Se relaciona con prácticas y mecanismos asociados con comisiones de la verdad, reformas institucionales, programas de reparación, archivos de Derechos Humanos, memoria, memorialización, políticas públicas, museos, perdones etc. (Hinton, 2010; Sieder, 2002; Wilson, 2001). En Colombia, se ha debatido la importancia de establecer derechos a las víctimas tanto de primera generación, como de segunda, haciendo énfasis en la justicia restaurativa (Uprimny et al., 2006). Esta discusión es central para entender el alcance de la perspectiva transnacional desde el punto de vista de reformas formales y/o estructurales.

4 Empleo el concepto de estado con minúscula como parte de un proyecto teórico amplio crítico de los estudios del estado señalado por Abrams (1988). Este uso tiene el propósito de aludir a las características metafísicas (culturales) del estado, así como de las manifestaciones más ubicuas y cotidianas. El estado no es una entidad abstracta con poder inmanente, sino prácticas, creencias y discursos concretos de diferentes actores sociales, incluso de aquellos que más se oponen a él.

5 En este artículo solo hago alusión a dispositivos de memoria y verdad histórica, sin hacer referencia al vasto desarrollo de otros mecanismos de verdad judicial implementado en Colombia 
una interpretación más general de la relación entre derecho y sociedad en Colombia.

Además, se reconoce la justicia transicional como un discurso emergente (2005-2011), que disemina los conceptos de memoria, justicia y verdad en instituciones públicas y organizaciones sociales. Al ver estos conceptos como formaciones discursivas, con sus propias reglas y normas, encontramos que la justicia transicional es un sistema de posibilidades conceptuales que determina horizontes de significado, pero también límites de pensamiento en un contexto y tiempo dados. De igual modo, algunas prácticas sociales reinterpretadas por este discurso encuentran resonancia por medio de efectos propios de la consolidación de esa forma de pensamiento. Así, si bien la justicia transicional es un horizonte de significado que ha problematizado particularmente el pasado de la violencia en Colombia, plantea efectos inesperados sobre la manera como se interpreta el conflicto político desde la perspectiva institucional y las organizaciones de víctimas, a la vez que plantea interesantes preguntas sobre la emergencia de horizontes de pensamiento que visibilizan el presente y el futuro como problemas.

El artículo sostiene que las formas sociales que adquiere la Ley en sus apropiaciones y resistencias colectivas e individuales, contrastan con los mecanismos jurídicos que la Ley articula, al no lograr responder adecuadamente al problema de la justicia y, con ella, a la verdad jurídica. ${ }^{6}$ La Ley como mecanismo de justicia transicional no es adecuada, porque no logra alcanzar su objetivo respecto de la justicia, pero resulta relevante al estudiar sus efectos en las instituciones públicas, ${ }^{7}$ la sociedad y la cultura. Para

(desarrollo de la justicia especializada, sentencias de la Corte Suprema de Justicia, sentencias de jueces de justicia y paz, el trabajo de la Unidad de Justicia y Paz de la fiscalía, las audiencias públicas, los incidentes de reparación, etc.). Tampoco hago referencia a los mecanismos e instituciones de reparación a las víctimas, que son ampliamente desarrollados sobre todo con la Ley de Víctimas y Restitución de Tierras a partir del año 2011.

6 Existe una larga tradición en los estudios socio-jurídicos (McCann, 1994; Rossenberg, 2008) y la antropología (Ferguson 1994) sobre el problema de las consecuencias inesperadas del derecho y de la política pública. Los socio-jurídicos se han negado a ver la ley o el derecho como un producto final y acabado. Por el contrario, la tradicional distinción de los realistas respecto del derecho en los libros y el derecho en acción, ha sido central para entender la complejidad de la aplicación de las normas cuando estas son apropiadas por instituciones y sujetos. Colmadas de consecuencias inesperadas, las nuevas leyes y políticas rara vez logran sus objetivos (Barclay et al., 2011), lo que no implica necesariamente que todas las acciones tengan efectos negativos.

7 Hay importantes cambios institucionales tras la incorporación de la legislación y mecanismos transicionales que promovieron reformas en la Fiscalía General de la Nación y los Ministerios del 
desarrollar este argumento, en la primera parte de este artículo se discutirá el trabajo de dos instituciones gubernamentales y/o públicas: la Comisión Nacional de Reparación y Reconciliación -en adelante CNRR-, de orden nacional y, en particular, el trabajo del Grupo de Memoria Histórica -en adelante GMH-; y el Centro de Memoria, Paz y Reconciliación -en adelante CMPR-, creado por el gobierno distrital de Bogotá. Con base en entrevistas y observaciones realizadas entre los años 2008 y 2010, se estudia la relación entre estado y memoria en dos ámbitos institucionales diferentes, para explorar sus articulaciones, tensiones, debates y dilemas, así como su articulación y resistencia a la Ley de Justicia y Paz.

En segundo lugar, presentaré el caso de dos organizaciones no gubernamentales: el Movimiento Nacional de Victimas de Crímenes de Estado (Movice) e Hijos e hijas: por la memoria y contra la impunidad. Estas organizaciones surgen como respuesta y resistencia a la Ley de Justicia y Paz, y representan un punto de partida crucial para entender los efectos inesperados del derecho en Colombia (o sus externalidades), los debates sobre la interpretación de la violencia reciente, la tensión que se identifica entre ellas y las experiencias, ideas y representaciones del estado. Igualmente, esta interpretación parte de entrevistas y observaciones etnográficas realizadas durante el mismo periodo.

Las instituciones públicas y las organizaciones sociales que por diferentes circunstancias han desarrollado mecanismos para materializar el derecho a la verdad y la memoria, o que han apropiado, trasformado y resistido sus mensajes, resultan ser lugares adecuados para entender la dimensión de prácticas, conceptos e ideologías que postulan un marco más amplio de comprensión de la democracia, incluso más amplio que el mismo multiculturalismo. En este artículo, simplemente, se muestra el potencial del derecho a la verdad y la memoria dentro de las instituciones y las organizaciones sociales para transformar las ideas más establecidas sobre el pasado, el presente y el futuro en Colombia.

El artículo da cuenta de cómo este nuevo ciclo de institucionalización de las memorias se da en un contexto social y político en el que las ideas

Interior y Justicia, y crearon instituciones como la Comisión Nacional de Reparación y Reconciliación (CNRR) en 2005, la Unidad para las Víctimas (UARIV), el Centro Nacional de Memoria Histórica, la Unidad de Restitución de Tierras, la Unidad Para la Atención a Víctimas y la Agencia Colombiana para la Reintegración en 2011. 
y las prácticas transicionales se diseminan en un estado y una sociedad, como se ha dicho, sin transición, y donde las adopciones y resistencias de los principios y mecanismos transicionales han transformando algunas formas tradicionales de reflexión y construcción del pasado, así como la interpretación gubernamental del conflicto. En el texto se afirma que la apropiación y desarrollo de la Ley de Justicia y Paz, en relación con los derechos a la verdad y la memoria de las víctimas, articula un debate más o menos amplio sobre el pasado y su función, que transforma no solo el marco de interpretación del conflicto, sino la orientación de la discusión política. Así, el problema de la verdad y la memoria desbloquea la polarización creciente, ofreciendo salidas sociales y culturales alternativas. De este modo, la política pública de reincorporación de excombatientes a la sociedad trajo consigo una epistemología transicional que entra a debatir con fuerza los usos del pasado, buscando ampliar el debate democrático. Como esta perspectiva presupone, estos procesos no son conscientes, ni mucho menos planificados. Es más bien el debate público y colectivo lo que les va dando sentido. A continuación se intentará mostrar cómo han ocurrido estos procesos sociales y políticos en medio de luchas y restricciones sociales y políticas.

\section{Grupo de Memoria Histórica}

La CNRR fue creada en el año 2005 por mandato de la Ley 975 (o Ley Justicia y Paz), con el objetivo de "facilitar los procesos de paz y la reincorporación individual y colectiva a la vida civil de grupos al margen de la ley, garantizando los derechos de las víctimas a la verdad, la justicia y la reparación" (Vicepresidencia de la República, 2010). Una de las tareas a cargo de la CNRR fue asegurar la participación de las víctimas en los procesos de investigación judicial y el cumplimiento de sus derechos. También tuvo la responsabilidad de hacer un informe público sobre los motivos y la evolución de los grupos armados ilegales. ${ }^{8}$ Para lograr esas metas fue

8 Han existido comisiones destinadas al estudio de los motivos del conflicto que son anteriores a la CNRR y que, como esta última, han sido nombradas por el gobierno. Para ver esto con más detalle consultar en Jaramillo, J., (2011). Expertos y Comisiones de estudio sobre la violencia en Colombia. En Revista de Estudios Políticos, (39). pp. 231-258. 
creada el Área de Memoria Histórica que estuvo conformada por un grupo de académicos (historiadores, abogados, psicólogos, antropólogos, entre otros), ${ }^{9}$ quienes se encargaron de desarrollar diferentes líneas de investigación cuyo objetivo fue la reconstrucción de las múltiples facetas del conflicto armado, así como las dinámicas, los actores y la evolución de los grupos armados desde 1964.10

Con la Ley de Justicia y Paz el concepto de derecho a la verdad se diseminó con dos nuevos sentidos: la verdad jurídica y la verdad histórica. Mientras que la primera quedó en manos de las autoridades judiciales y se convirtió en uno de los aspectos más críticos de la aplicación de la Ley, la segunda quedó en manos de la CNRR, siendo hasta la fecha ampliamente desarrollada por el GMH desde la perspectiva de la "memoria histórica". Dentro de las diferentes líneas de investigación, el GMH desarrolló los temas de género, aspectos socioeconómicos y tenencia de la tierra, aspectos políticos, estética del terror y la violencia, el narcotráfico, así como de los mecanismos del despojo y desplazamiento. Cada una de las líneas de investigación fue dirigida por un investigador principal especialista en el tema y dos asistentes de investigación quienes desarrollaron proyectos particulares con el soporte de un investigador principal.

Según uno de los investigadores del GMH, la "memoria histórica" estaba ligada a dos líneas de investigación. Por un lado, al método histórico, que recurre al testimonio y documentos de prensa y archivo, y, por el otro, al método jurídico, que recurre a pruebas. La conjunción de ambos métodos "permitía triangular la narración, datos, testimonios y pruebas, si no, no era posible incluirlo dentro del informe" (Asistente de investigación GMH, entrevista realizada el 9 de marzo de 2009). Igualmente, los informes combinaban el testimonio con el estudio del contexto social, político y económico en el cual ocurrieron los hechos. De este modo, los informes se han convertido

9 Desde 1987 los estudios sobre violencia se han intensificado en Colombia, debido a la aparición de un grupo de académicos de diferentes disciplinas que integraron el grupo conocido hoy como los violentólogos. Estos afirmaron que las causas de la violencia en Colombia estaban relacionadas con condiciones materiales en las que la pobreza -como problema central- reproducía una endémica desigualdad social. Al mismo tiempo, aseguraron que la violencia en Colombia no solo estaba relacionada con el conflicto armado, sino con varias manifestaciones (violencia política, crimen organizado, violencia doméstica y violencia étnica) articuladas a problemas estructurales. Esta visión no se reflejó tan claramente en los informes del GMH.

10 Al finalizar, el informe final Basta Ya, entregado en 2013, inicia su estudio en 1958. 
en tecnologías de memoria en sí mismos, no solo por su contenido, sino porque son objetos que construyen -individualmente y en conjunto- una narrativa específica, que amplifica iniciativas de memoria y de visibilización de hechos ocluidos. ${ }^{11}$

Dentro de los efectos más significativos que han tenido estos informes, se halla el de la apropiación que han hecho de ellos los diversos actores sociales como víctimas, jueces y académicos. En el caso del primer informe sobre Trujillo, por ejemplo, parte de las investigaciones históricas y los elementos del contexto sociopolítico allí desarrollados han sido usados por los jueces para hacer imputaciones y producir parcialmente verdades legales, ${ }^{12}$ como argumenta un asistente del GMH:

[...] nuestro interés real es la memoria, pero eso no significa que en el proceso no encontremos verdades. Aun así, nuestro rol es ayudar a construir la memoria histórica. Nosotros tratamos de hacer claro esto en todas partes. Sin embargo, lo que está pasando es que nuestros reportes están siendo tomados como verdad judicial o están siendo usados como partes de archivo o prueba judicial. Pero nosotros solo queremos contribuir a la clarificación histórica (Asistente de investigación GMH, entrevista realizada el 14 de mayo de 2009).

Mirados en conjunto, hoy puede afirmarse que los informes no conservan unicidad metodológica. En cambio, profundizan en los métodos y la especialidad de cada investigador. Igualmente, se puede afirmar en

11 Del año 2008 al 2011, el GMH publicó 12 informes. Algunos de ellos fueron denominados "casos emblemáticos" mientras otros se constituyeron como informes temáticos. Es decir, estudios relacionados con problemas transversales pero específicos como la tenencia de la tierra, el despojo, la violencia de género o versiones libres. En particular, lo que se denominó "casos emblemáticos", eran estudios que buscaban representar la diversidad de actores involucrados en el ejercicio de la violencia, para evitar la proyección de una única versión de los hechos y, en su lugar, incluir la multiplicidad de actores y formas de violencia. En su conjunto esta variedad de productos se han convertido, para la comunidad académica y para algunas víctimas, en los productos más visibles del grupo y, al mismo tiempo en el dispositivo de institucionalización de la memoria de la violencia más reciente en el país.

12 Para los investigadores del GMH esta experiencia es una muestra del reconocimiento del carácter político y práctico de las reconstrucciones de la memoria. Por eso, a partir de este caso el GMH desarrollaba una serie de propuestas que sirvieran de manera específica a los habitantes del municipio de Trujillo, así como, en general, al desarrollo de una política pública sobre la reparación a las víctimas. El GMH hacía recomendaciones puntuales a instituciones específicas. Frente a eso, la Procuraduría General de la Nación ha emitido directivas que les dan sustento jurídico a estas recomendaciones, dado que el GMH no poseía dicha facultad. 
congruencia con un investigador del GMH, que "los informes no son exclusivamente recuperaciones de memoria". ${ }^{13}$ Más bien, son casos que combinan las voces de las víctimas y de los investigadores con el análisis académico para entender las causas socio-políticas y económicas que hicieron posibles los hechos victimizantes descritos en cada informe. ${ }^{14}$ Esto no solo da cuenta de las elecciones metodológicas y temáticas que los autores de los informes tomaron con el tiempo, sino que también revela restricciones materiales y formales que sugiero también han dado forma a dichas elecciones.

Por ejemplo, a diferencia de lo que sí pueden hacer ahora, durante la vigencia del GMH (2005-2011), los investigadores no estaban en la posición de publicar hallazgos que no hicieran parte de procesos judiciales concluidos. Esto debido a que podrían enfrentar demandas o intervenir en procesos judiciales en curso. ${ }^{15} \mathrm{Al}$ mismo tiempo, los informes tenían que minimizar posibles procesos de revictimización, dado que el conflicto continúa. También se enfrentaban a dificultades asociadas a su filiación con el estado y el problema que con ello trae crear confianza entre las comunidades y las organizaciones sociales. Por otra parte, como lo señalan algunos investigadores, para elegir los casos estos estaban sujetos a que tuvieran avances judiciales, propiciando, como lo menciona un investigador del GMH, que los informes también crearan "exclusiones y jerarquizaciones". Esta situación también estaba ligada, como lo está ahora, a que, por un lado, el conflicto continúa y "se investigue lo que se pueda investigar", y por el otro, lo que se puede llamar la economía política del humanitarismo en Colombia. ${ }^{16} \mathrm{De}$

13 Asistente de investigación GMH, entrevista realizada el 14 de mayo de 2009.

$14 \mathrm{Al}$ respecto, un asistente de investigación del GMH comentaba: "A pesar de que todas las líneas suponen el estudio de la memoria, la memoria realmente solo se encuentra explícitamente en el proyecto de María Victoria Uribe sobre iniciativas no oficiales de memoria. Los demás proyectos academizan, al hacer énfasis en ubicary desarrollar el contexto histórico. De algún modo, lo que se hace es privilegiar la rigurosidad académica dejando de lado el tema de la memoria" (Asistente de investigación GMH, entrevista realizada el 14 de mayo de 2009). Otros elecciones y restricciones plantean, como en el caso de Trujillo, que "se investigara lo que se pudo, no lo que se quiso" en tanto el trabajo dependía de la apertura de los informantes.

15 Los investigadores no podían hacer afirmaciones que no estuvieran soportadas por una investigación judicial. Por ejemplo, en el informe de La Rochela "no se pudo ir más allá de lo que existía en prensa y los expedientes" (Asistente de investigación GMH, entrevista realizada el 18 de marzo de 2009). Ahora, con la nueva ley de víctimas, quienes realizan procesos de investigación en el Centro Nacional de Memoria Histórica no podrán ser judicializados.

16 Las exclusiones y jerarquizaciones se enmarcan también dentro de la economía política del humanitarismo, que ha sido más explorada desde el punto de vista de la gubernamentalidad (Li, 2007; Fassin E Rechtman, 2009), aunque requiere toda la atención en cuanto a la creación 
este modo, los informes seleccionan, limitan y modelan interpretaciones, ya sea por las dificultades del contexto o por la necesidad de minimizar la posibilidad de producir daño.

Con todo, la realización de este trabajo no ha sido fácil. Este ha requerido "ganarse la confianza de la gente" y "que la gente le encuentre sentido". La crisis del proceso organizativo durante este período y la relación del estado con la sociedad hicieron necesario que el entonces GMH se contactara con organizaciones de víctimas, teniendo que negociar con ellos y explicar detalladamente los procesos de reconstrucción de memoria y trabajo conjunto, como lo comentaba un asistente de investigación del GMH:

Es muy difícil la construcción de memoria cuando se es parte del Estado. Por un lado, ha sido difícil ganar legitimidad, especialmente dentro de las organizaciones de víctimas. Sin embargo, yo pienso que construir memoria desde instituciones gubernamentales tiene mayores impactos que los esfuerzos realizados por organizaciones sociales y ONGs. Especialmente en términos de la difusión... Yo pienso que el Estado alcanza sectores que estas organizaciones no logran. De todas maneras, el grupo no es responsable por la verdad o la verdad judicial, porque la verdad es muy difíil de investigar en medio del conflicto. Lo que nosotros estamos haciendo es trabajar en casos que ya han sido investigados, aunque este no es necesariamente el caso, porque al final, todo o casi todo, está por investigarse y ser dicho. (Asistente de investigación GMH, entrevista realizada el 14 de mayo de 2009).

\footnotetext{
de industrias durante las crisis humanitarias. Desde un punto de vista muy general, en el contexto colombiano vale enunciar que estas jerarquizaciones también se articulan a dispositivos discursivos sobre el desarrollo, la reconciliación, el conflicto y el posconflicto, provenientes de la relación técnica, financiera y burocrática asociada a la consecución de recursos de cooperación internacional (Usaid, Aecid, Unión Europea, Agencia Catalana de Cooperación, Embajada de Canadá, Embajada de Suiza, entre muchas otras), empresas y agencias locales (por ejemplo Telefónica, Argos, Fundación Semana, entre otras) y la financiación estatal. Buena parte de las investigaciones del GMH fueron financiadas por estas entidades de cooperación, mientras que los investigadores eran financiados por las universidades o instituciones en donde trabajaban. Además, se crean exclusiones por otras circunstancias asociadas a las políticas de reparación en el terreno, así la escogencia de unos casos excluye otros y la incorporación de algunas víctimas, excluye otras; lo mismo sucede con los enfoques de la política pública. Por ejemplo, la aplicación de beneficios a desmovilizados y la demora en la reparación a las víctimas en una misma comunidad o región genera tensiones y posicionamientos diferenciados cuando a los desmovilizados se les otorga una ayuda mensual y las víctimas esperan por sus indemnizaciones.
} 
Esta situación paradójica también se evidencia en las tensiones y contradicciones que la puesta en práctica de la "memoria histórica" produce. Por ejemplo, en el lanzamiento del primer informe realizado por el GMH sobre la masacre de Trujillo (Valle) se expusieron los pormenores del informe y del proceso de trabajo con las víctimas que realizaron algunos investigadores del GMH. En el evento intervinieron el director de la CNRR, el director del GMH y el vicepresidente de la República de la época. Seguidamente, habló la representante de las víctimas de Trujillo quien se refirió, entre varias cosas relevantes, a la fortaleza de los procesos organizativos de las víctimas, a la lucha que han ejercido, a la deuda del estado con estas víctimas, pero, sobre todo, fue clara en señalar la dificultad que han tenido en creer en el estado, incluso en creer en la CNRR. Sin embargo, acto seguido, reconoció el trabajo de Gonzalo Sánchez, director del GMH, y de los investigadores del grupo, agradeciéndoles por su trabajo y su esfuerzo en el proceso de investigación. Este esquema se repitió más o menos igual un año después con ocasión de la presentación del informe de El Salado, solo que esta vez se sumó el acto de perdón del vicepresidente de entonces. Durante este acto, el vicepresidente señaló a las FARC de ser en parte responsables de la masacre, dado que meses atrás de los hechos ocurridos, la guerrilla había expulsado a la policía del municipio. Su intervención responsabilizando a las FARC contrastaba con el contenido del informe y con la versión de las víctimas. Esto es interesante porque estos espacios deben verse como escenarios incipientes de la dramatización del perdón público y de la aceptación de responsabilidades.

Sin embargo, estas posturas de las víctimas y sobre las víctimas, visibilizan las fisuras que estructuran las representaciones de estas sobre el estado y permiten observar cómo este se presenta de manera arbitraria y con daño. En este caso en particular, el estado aparece ante las víctimas por medio de un acto ritual y solemne, como lo es el lanzamiento anual de los informes. Igualmente, se expresa por medio de la autoridad que ostentan personas que representan al estado. Pero también aparece de manera ambigua, contradictoria y accidentada, como cuando niega los avances del mismo en el esclarecimiento de la verdad histórica. ${ }^{17}$ En este sentido, los informes, como objetos valiosos de memoria, contrastan con la banalización

17 La verdad histórica, claro está, desde la perspectiva de las tecnologías de la verdad histórica; 
simbólica que se hace de ellos por la presencia de funcionarios que carecen de legitimidad ante las víctimas o que controvierten los desarrollos de algunas instituciones públicas en verdad histórica y jurídica. De este modo, las prácticas transicionales han hecho que componentes de ciertas instituciones estatales, como el GMH en este caso, se hayan puesto a prueba ante las víctimas y sus organizaciones, logrando legitimarse por cuenta del proceso mismo de investigación y producción de los informes, a pesar de que otras instituciones del estado continúan siendo ilegitimas, desde el punto de vista de las víctimas. El ejemplo arriba mencionado ilustra cómo, en un contexto de polarización creciente, el GMH logró construir una autonomía relativa respecto del resto de las instituciones públicas, incluso frente a la propia CNRR cuya entidad, en cabeza de su director, afirmaba que las víctimas en Colombia eran en su mayoría mujeres pobres del campo que solo querían perdonar. Al contrario, sin esperarlo el legislador, el GMH posicionó la "memoria histórica" como una responsabilidad del estado y movilizó su significado a través de diversas investigaciones y de la apropiación del concepto por algunas víctimas y comunidades.

El trabajo que ha desarrollado el GMH es central en la discusión sobre la producción de memoria en ámbitos gubernamentales como resultado de la apropiación de mecanismos de la justicia transicional. Si bien el GMH luchó con éxito para que no existiera ni filtro ni censura sobre sus informes e investigaciones, el contexto de violencia hizo que el grupo adoptara medidas de descripción y enunciación estratégicas que permitieran que la omisión de ciertos aspectos y el lenguaje académico protegieran la vida de las víctimas e incluso la vida de los investigadores. En este sentido, nos hallamos en un contexto de producción de memoria donde la "memoria histórica" -en la forma de casos emblemáticos y conmemoraciones- pasa por formas de regulación material, académica y legal que el mismo conflicto impone, y que dan forma al desarrollo de una verdad histórica más o menos restringida, formal y con efectos en la sociedad que aún están por evaluarse. Durante el período que aquí se estudia, las formas de difusión de los informes fueron muy limitadas, no solo por el precio de los mismos, sino porque estos solían divulgarse en recintos cuya audiencia era conformada

es decir como mecanismo de la justicia transicional ampliamente desarrollado por la CNRR a partir de la Ley de Justicia y Paz. 
en su mayoría por académicos y organizaciones de cooperación internacional, con poca resonancia en los medios masivos de comunicación.

\section{Centro de Memoria, Paz y Reconciliación (CMPR)}

El CMPR fue una iniciativa impulsada en el año 2008 por el director de la ONG INDEPAZ, Camilo González Posso, y miembros pertenecientes al gobierno de la Alcaldía de Bogotá, como Clara López Obregón y el concejal Fernando Rojas. Esta "iniciativa oficial de memoria" tuvo como objetivo "materializar el compromiso de dignificar la memoria de las víctimas y promover una cultura de paz y respeto por los Derechos Humanos, a través de la creación de un escenario de pedagogía y reflexión sobre el pasado y el presente de nuestro pais" (Centro Bicentenario Memoria, Paz y Reconciliación, 2009). La singularidad de esta iniciativa distrital radica en el desarrollo de una discusión sobre la necesidad de implementar una política pública en memoria. Gestores del CMPR retomaron este debate ampliamente desarrollado en países como Argentina y España para articular una perspectiva sobre el pasado reciente de la violencia política dando cuenta de las víctimas y de su papel en la lucha por la democracia.

El CMPR surgió como un proceso participativo a través de una mesa consultiva que no operó de manera notoria, y de la participación de diferentes organizaciones sociales y de víctimas. ${ }^{18}$ Este monumento se encuentra hoy en Bogotá sobre la calle 26, en el Parque de la Reconciliación, el cual incluye la construcción física del CMPR con salas de conferencias y exhibiciones, y un centro virtual. Desde su inicio, sus gestores debatieron el proyecto en seminarios nacionales e internacionales, charlas, mesas redondas y de asesoramiento, y desarrollaron proyectos tales como las "Cartografías de la memoria", que identificaban lugares representativos de la violencia política en Bogotá. Durante la construcción del CMPR sus promotores ejecutaron proyectos de memoria y educación. ${ }^{19}$ La actividad más relevante

18 Asfamipaz, Asfades, Reiniciar, entre otras.

19 La construcción y concepción del CMPR son dos procesos paralelos que pasan por darle significación al espacio donde fue construido y el desarrollo del concepto de política pública de la memoria. 
fue la iniciativa llamada "Tierra sembrada de memoria" entendida como una "forma de dar tributo a las víctimas, de expresar solidaridad y dejar un testimonio colectivo de que los Derechos Humanos y la dignidad son para todos" (Centro Bicentenario Memoria, Paz y Reconciliación, 2009). Esta tierra se ha alojado en pequeños tubos de vidrio que se introducen a su vez en calas hechas con este fin en la estructura central del edificio del CMPR. Esta estructura se denomina "el monolito". Luego de su construcción se han incorporado más tubos en actos solemnes, como el que recientemente hizo Ecopetrol y la USO como símbolo del acuerdo marco para la reconstrucción de la memoria histórica entre la empresa y el sindicato.

$\mathrm{Al}$ igual que en el caso del GMH, el proyecto del CMPR inició en el 2008, en pleno auge de una lectura gubernamental que negaba la existencia del conflicto armado. Como una reacción ante esta relectura gubernamental del conflicto, los gestores del CMPR plantearon una discusión sobre las políticas de la memoria y el problema de la memorialización, ${ }^{20}$ discusiones que tradicionalmente tienen lugar en contextos de fin del conflicto e incluso suceden muchos años después de que estos ocurran, como en Alemania, España, Argentina o Chile, por nombrar algunos casos. Este aparte propone una interpretación del proceso de configuración del CMPR, que por sus características institucionales respondió a una iniciativa gubernamental pero que en la práctica fue impulsada por un sector de la sociedad tradicionalmente excluido del sistema político y de gobierno, que también se

20 La apropiación de la justicia transicional en Colombia ha abierto de manera importante el debate sobre la memorialización, que problematiza la construcción de museos, monumentos y memoriales, las paradojas inscritas en las maneras de recordar, honrar o conmemorar a las víctimas, así como el lugar de los victimarios en el relato producido. El debate sobre construir estos espacios de reconstrucción de la memoria es central desde la formación del Estado-Nación. Autores como Adorno se opusieron de manera radical a la conmemoración de eventos como el Holocausto, en tanto conmemoración de la barbarie, replicando la monumentalización fascista. Sin embargo, desde la Segunda Guerra Mundial emergen instituciones como los museos de la memoria (el museo del Holocausto en Berlín, Jerusalén, Washington, Houston, etc., por ejemplo). Otros autores han llamado la atención sobre la importancia del carácter público del monumento y su papel en la transmisión de la memoria cultural (Young, 2000). Por otra parte, el memorial puede tener un carácter más dinámico y ser objeto de resignificación por parte de quienes le dan uso o lo interpretan; este es el caso del memorial de los veteranos de la guerra de Vietnam en Washington (Sturken, 1997, p.5). Hay monumentos concluidos que dan cuenta de una interpretación de lo conmemorado, pero también está el memorial o contra-monumento, que deja espacio para la interpretación y apropiación de la memoria. Catalina Martínez (2012) señala que el CMPR reúne las características de un memorial, en tanto invita al espectador a reflexionar, a mantener la memoria viva y a condenar los hechos violentos (Martínez, 2012, p.17). 
ha considerado víctima del conflicto y perteneciente aún hoy a la órbita del gobierno distrital. ${ }^{21}$

Durante su conceptualización, el CMPR es visto como un memorial que reconoce las víctimas de la sociedad colombiana en el contexto del conflicto armado en Colombia. Intenta dar cuenta de las víctimas de una manera colectiva y no individual, destacando el carácter de la invisibilidad histórica de los colombianos que han perecido por causa directa o indirecta de la guerra. ${ }^{22} \mathrm{El}$ desarrollo de esta iniciativa involucró esfuerzos por discutir qué clase de memorial sería, qué objetos pondrían estar allí, qué período debería abarcar, y qué clase de narrativa y representaciones debería tener. Debido al contexto sociopolítico en el cual fue planeado y construido el memorial, el proyecto mismo enfrentó disputas entre los diferentes grupos y organizaciones convocados.

Por un lado, y al igual que los miembros del GMH, los gestores del CMPR tuvieron que superar la "carga" de ser parte de una iniciativa gubernamental a los ojos de los actores no institucionales y estatales. Por otro lado, se enfrentaron a las tensiones entre las diferentes organizaciones que reivindicaban variadas formas de victimización. Igualmente, algunas organizaciones criticaban los posibles sesgos que el CMPR podría tener dada, por ejemplo, la ausencia de representantes de grupos étnicos y, en ese entonces, de representantes de población desplazada. De ahí surgieron retos centrales en la estructuración del Centro, entre los que estaban la definición de cuáles o quiénes serían las víctimas conmemoradas, cuál o cómo se debería abordar una narrativa y, sobre todo, cuáles serían las garantías para las víctimas. ${ }^{23}$ Algunas organizaciones criticaron el énfasis de esta iniciativa en conmemorar las víctimas del paramilitarismo y agentes del estado, y de poner poca atención a las víctimas de la guerrilla. Otros

21 Para ver en detalle un trabajo profundo sobre el diseño de la política pública de la memoria en Bogotá elaborada sobre la construcción de este CMPR ver Martínez Sarmiento, C. (2012). Memorialización y políticas públicas de la memoria en Bogotá: Centro del Bicentenario Memoria, Paz y Reconciliación (Tesis pregrado, Pontificia Universidad Javeriana, Bogotá, Colombia).

22 Según el informe Basta Ya del GMH entre el primero de enero de 1958 y el 31 de diciembre de 2012 perecieron 220.000 a causa del conflicto.

23 Este aspecto es clave en tanto las organizaciones de víctimas son conscientes de la dificultad de garantizar la sostenibilidad de una política pública de la memoria, puesto que estas iniciativas están enmarcada en proyectos que, por sus características políticas y la forma en que se configura el estado colombiano, están al vaivén de los administraciones de turno y no de políticas públicas sostenidas y duraderas. 
sectores manifestaban su preocupación por la formalización y apropiación de la memoria de la violencia que suponían iniciativas como esta, lideradas por instituciones públicas.

Aunque el CMPR también fue una iniciativa gubernamental y pública, representa un proyecto de memoria diferente al que perfiló el GMH. Mientras que la función general del GMH como parte del gobierno nacional era presentar un informe público sobre las razones del surgimiento y evolución de los grupos armados ilegales, el CMPR fue una iniciativa del gobierno distrital promovida por miembros de organizaciones no gubernamentales y la administración distrital para conmemorar a las víctimas de la violencia y visibilizar los procesos democráticos y de construcción de paz de la ciudadanía. Mientras que el GMH se encargó de diseminar el concepto de "memoria histórica", el CMPR promueve el problema de la memorialización y de la "memoria ejemplarizante" o memoria democrática. ${ }^{24}$ Para esto es necesario, según miembros del CMPR, la elaboración, recuperación y conservación de la memoria e impulsar procesos para que esta permanezca viva y sea objeto de constante reflexión.

En este sentido, fue en el proceso de conceptualización del CMPR donde tuvo lugar el debate explícito de las políticas públicas de la memoria. Si bien el GMH fue uno de los protagonistas en el desarrollo de prácticas, discursos y políticas de la memoria, hasta la fecha se ha abstenido de ser parte activa y directa de este debate, mientras que el CMPR ha hecho de esta discusión la plataforma central de su posicionamiento académico y político. Con la discusión de los marcos internacionales sobre el deber de memoria que le corresponde al estado, el CMPR ha introducido los debates sobre las políticas públicas de la memoria en España y en el Cono Sur, así

24 Esta visión se inspira en la resignificación del peso de la memoria franquista en la España de pos-dictadura, que exaltó la lucha por la democracia y a quienes dieron su vida por esta, sirviendo como patrón analítico del pasado glorioso de la dictadura. En este caso, se intercepta la democracia como espacio de resignificación y la política pública de la memoria como formas de intervenir en la construcción del pasado respecto de la modificación o perpetuación de la memoria hegemónica (Vinyes, 2004). De este modo, quienes concibieron el Memorial Democrático en Barcelona, que conmemora la lucha por la democracia, la guerra civil, la posguerra y la represión (Vinyes, 2004) sugieren que el fundamento de las políticas públicas de la memoria sea la "transmisión de la democracia", es decir, de los valores éticos y las prácticas de resistencia y transgresión de todos los ciudadanos que le hicieron frente a la violencia política dada la negativa de los estados en reconocer que fue gracias a ese patrimonio ético que se abrieron nuevamente los caminos hacia la democracia (Guixé E Inesta, en Martínez, 2012, p. 34). 
como el paradójico problema que esto implica como propuesta de regulación de memoria.

En este contexto, en junio del año 2009 participé en un seminario llamado "Documentación y archivos para la memoria", organizado por el CMPR. Su objetivo fue identificar las dificultades y alternativas de preservar los archivos de Derechos Humanos desde la perspectiva de organizaciones locales de víctimas, organizaciones internacionales como Memoria Abierta y el Museo de Anne Frank, así como de investigadores y académicos. Si bien muchos de los retos que han afrontado las organizaciones de víctimas en Latinoamérica respecto de la construcción de archivos y centros de documentación se han dado en situación de post-guerra o post-dictadura, en Colombia la discusión ocurre en medio del conflicto, en el que persiste la violación de los Derechos Humanos, a la vez que emergen y se adoptan en el país diferentes estándares de justicia en contextos de transición en medio del conflicto.

Participar en este encuentro me permitió entender las paradojas, los obstáculos y las tensiones que rodearon la formulación del CMPR y reconocer las tensiones que embarga su articulación con un archivo de violaciones de Derechos Humanos en un contexto de violencia y estigmatización política. Primero, era claro que las organizaciones de víctimas y las $O N G$ poseen una vasta experiencia en la creación de archivos de Derechos Humanos. ${ }^{25}$ Para muchas de las organizaciones presentes, este tipo de archivos representa no solo un instrumento de conservación de la memoria, sino un objeto de consulta pública y académica en un contexto democrático, así como base para una eventual comisión de la verdad y la apertura de procesos judiciales.

Durante la discusión que realizaron los asistentes surgieron preguntas fundamentales para aproximarse a los dilemas inesperados de los mecanismos de la justicia transicional en Colombia, entre estas, ¿de qué manera podemos las organizaciones sociales victimizadas entregarle a las instituciones públicas los archivos que preservamos y que hemos construido, cuando el mismo estado ha negado nuestra victimización y, a veces, ha sido cómplice o victimario directo?, ¿cómo podemos garantizar que el museo

25 Por ejemplo, el CINEP ha recopilado una base de datos sobre violación de Derechos Humanos desde mediados de la década de 1980, con miras al establecimiento de una eventual comisión de la verdad en Colombia. 
no se vuelva tan solo un museo de piedra?, ¿cómo lograr el cumplimiento de las obligaciones públicas?, ¿cómo armonizar lo que hace el estado con las organizaciones de víctimas?

Como se puede sospechar, los archivos, memoriales y museos poseen gran valor social, político, legal y cultural, y de ahí su situación paradójica en contextos de conflicto. En este sentido, y en línea con las preguntas anteriores, ¿cómo pueden las víctimas y las organizaciones que las representan compartir la información que han recolectado, la investigación que han producido, los archivos que han creado e incluso protegido, cómo pueden ellos garantizar la seguridad, la conservación y cuidado de estos archivos con cambios de gobiernos locales y nacionales, y más hoy en medio del conflicto, en un contexto en el que no se ha consolidado una transición política o institucional?

Todas estas preguntas dejan entrever que los problemas asociados al archivo y al memorial son centrales como tecnología de memoria y a los usos inesperados del derecho, en tanto representan un espacio de conservación, selección y almacenamiento, pero al mismo tiempo y, bajo otra luz, resulta ser un mecanismo típico de la justicia transicional. El archivo se ha constituido como lugar central de las luchas por la memoria en contextos de post-conflicto, donde no solamente se busca un lugar en la memoria colectiva, sino consolidar un espacio material que le dé vida para que perdure en el tiempo. Sin embargo, estos archivos y memoriales no son fáciles de crear y requieren tiempo, trabajo y voluntad por parte de sus gestores, los estados y las organizaciones sociales para su construcción. Ejemplo de esto son los archivos de la policía en Argentina o los archivos de la Gestapo en Alemania (topografías del terror), que hoy se constituyen como centros de investigación y documentación.

Los archivos en general, y los archivos de violación de Derechos Humanos en particular, resaltan un principio ordenador que articula la pesquisa histórica con su disposición hacia una lectura en el presente y el futuro, que puede respaldar todo un horizonte de sentido histórico. De este modo, la problematización del archivo como lugar en el que la cultura material (retratos, fotos, documentos) e inmaterial (testimonio, historia oral) se recoge, selecciona, organiza y conserva (entre estos la variedad de archivos 
personales, judiciales, históricos y/o administrativos), se convierte en la base de lo que puede ser dicho en el futuro sobre el presente. ${ }^{26}$

Por esto, las preguntas que formularon las organizaciones sociales son pertinentes para entender la reinserción del problema museológico y archivístico dentro del estado y la sociedad en conflicto. Así como el multiculturalismo despertó debates museológicos más o menos intensos, al punto que el guión oficial de culto a los héroes y el esquema teleológico del Museo Nacional se retematizó, la justicia transicional está transformado la producción y circulación histórica hegemónica tradicional, centrada en las instituciones, los partidos, sus héroes y la violencia política. ${ }^{27}$ En este sentido, la relación del archivo y el memorial con la justicia transicional no es superficial, y abre un camino de reflexión en torno al problema de la democracia por construir, sobre la base de esa nueva forma de hacer historia, así como evidencia la variabilidad del carácter público de la memoria planteando una concepción sobre el pasado muy diferente al del caso examinado por el GMH.

Aunque el trabajo del CMPR ha sido vital para el desarrollo de tal debate, este último se ha dado en los extramuros de donde se plantean y diseñan las políticas públicas de la memoria. Igualmente, el hecho que esta discusión haya ocurrido en medio del conflicto, que haya tenido solo alcance distrital y que se diera en medio de la polarización política del conflicto,

26 Con la Ley de Víctimas y Restitución de Tierras se encomendó al Centro Nacional de Memoria Histórica (CNMH) la tarea de construir un museo de la memoria y un archivo de Derechos Humanos. En el proceso de discusión y socialización que ha lleva a cabo el CNMH sobre la construcción de este archivo encontramos disputas referentes a la pertinencia del mismo archivo por parte de funcionarios de otras instituciones, como el Archivo General de la Nación. También se han identificado temas como la escasa tradición archivística nacional, el estado material de los archivos generales y regionales en Colombia, la falta de reglamentación y lineamientos, así como la falta de una ley adecuada que vele por la información de los archivos públicos.

27 El debate entre la antigua curadora del Museo Nacional, Beatriz González, y Cristina Lleras, quien la precedió, articula de manera ejemplar este debate. Para la celebración del bicentenario de la independencia, Cristina Lleras transformó el guion del museo casi de manera definitiva. En vez de exaltar la memoria oficial y sus próceres, decidió hacer preguntas alrededor de la construcción y representación histórica misma y resaltar la ausencia de las mujeres, los mulatos, los negros y los indígenas en estos relatos heroicos, haciendo una interpretación más inclusiva de la identidad nacional, donde lo popular y una narrativa crítica lograron desacralizar a los héroes, situando lo histórico en los esclavos, los llaneros, los indígenas y aquellos otros que han luchado por la ciudadanía. En pocas palabras, decidió darles un lugar en la historia. Cristina Lleras articuló la crítica que hizo Gonzalo Sánchez en el libro compilado Memoria, Museo y Nación del año 2000. Por su parte, Beatriz González criticó la desaparición de la sala fundadores. Ver Junca H., (2011). La misión del museo no es permanecer lleno de gente, sino preservar la memoria del país. Revista Arcadia 68: pp.12-13. 
no permitió un debate de alcance nacional. Sin embargo, podemos decir que dentro de las consecuencias inesperadas de la Ley de Justicia y Paz, se encuentra la relegitimación de los procesos de memorialización. De hecho, esto plantea diferentes apuestas y luchas por la interpretación del pasado violento dentro de las mismas instituciones públicas, como el desarrollo, en este caso, de una concepción de la "memoria democrática" que se entrecruza y superpone con la de las organizaciones sociales y que destaca el pasado de la violencia política, no como un período que ha dejado víctimas, sino que resalta la lucha constante de la sociedad por la ciudadanía y la democracia. En este sentido, se busca la amplitud y el desplazamiento de la historia democrática, centrado tradicionalmente en la historia de las instituciones y los partidos políticos.

Para entender la importancia de la diseminación de discursos y prácticas de la justicia transicional, resulta importante aproximarse a la visibilización, apropiación y transformación de nociones de memoria que transitaban por fuera de la interpretación dominante del conflicto armado (como lo ha sido la violencia como objeto histórico, por ejemplo). Sin embargo, es bajo la luz de los discursos y prácticas de la justicia transicional que organizaciones de víctimas e iniciativas de memoria y justicia emergen con nuevos sentidos y fuerzas renovadas, movilizando otros conceptos, como el de memoria democrática o reivindicativa. Las particularidades del CMPR en su constitución y en su articulación intelectual comparten algunos rasgos con las organizaciones sociales que emergieron en respuesta explícita a la promulgación de la Ley de Justicia y Paz. Estas organizaciones son cruciales para examinar y discutir algunos de los dilemas planteados arriba por organizaciones de víctimas en congresos y seminarios respecto las iniciativas institucionales y políticas públicas de la memoria, e indagar sobre las consecuencias inesperadas de la Ley de Justicia y Paz.

\section{El Movimiento Nacional de Víctimas}

Este movimiento representa la fase más reciente de una larga historia de movilización política y social para el reconocimiento de las víctimas por agentes institucionales. Esta no es una organización unificada, sino una red de grupos sociales que desde el año 2005 se reúne alrededor del Comité 
de Impulso del Movice (Movimiento Nacional de Víctimas de Crímenes de Estado), que surgió en el marco de encuentros nacionales de víctimas, en los que se estableció la necesidad de responder ante la violación de Derechos Humanos por diferentes grupos armados y agentes del estado. Entre el 28 y 29 de mayo del 2004 se llevó a cabo el primer encuentro nacional de víctimas de crímenes de lesa humanidad y violaciones a los Derechos Humanos. El 25 de junio del 2005, después de la promulgación de la Ley de Justicia y Paz, el movimiento fue creado oficialmente en el segundo encuentro de víctimas, que se realizó en varias regiones del país como Cartagena, Medellín, Cali, Popayán, Barrancabermeja, Bucaramanga y Bogotá.

El problema de la verdad, la justicia y la reparación no era un tema nuevo para el Movice. Sin embargo, el marco conceptual e interpretativo de la justicia transicional le dio un nuevo impulso al movimiento de víctimas. En 1995 buena parte de las organizaciones pertenecientes hoy al Movice desarrollaron el proyecto "Colombia nunca más", que constituía un esfuerzo para documentar violaciones de Derechos Humanos a partir del año 1965 (Herrera, 2008). Mediante este proyecto se buscó salvaguardar la memoria histórica de las víctimas del conflicto armado y construir un archivo de Derechos Humanos. Este proyecto fue desarrollado por 17 organizaciones sociales, las cuales documentaron más de 41.000 crímenes hasta 2010.

La emergencia del Movice responde a la falta de reconocimiento de las víctimas en la Ley de Justicia y Paz, y al reclamo de incluir el derecho internacional de los Derechos Humanos y el Derecho Internacional Humanitario en los procesos de justicia y paz. ${ }^{28} \mathrm{Si}$ bien en Colombia predominaba antes del año 2005 el concepto de "desplazado interno" (en el derecho internacional DFI, desplazamiento forzado interno), como marco interpretativo de la crisis humanitaria vivida en el país desde mediados de la década de 1990, la Ley de Justicia y Paz transformó dicho marco interpretativo y la comprensión misma de la "crisis humanitaria" al introducir el concepto

28 El Movice no solo rechazó la Ley de Justicia y Paz, sino que demandó la Ley de Víctimas y Restitución de Tierras en 2011 por ser restrictiva frente a los derechos de igualdad de las mismas. Esta posición está influenciada por la discusión que gira en torno al conflicto armado, y si este -en relación con las víctimas- debe ser cobijado por el derecho internacional humanitario (DIH) o por el derecho internacional de los Derechos Humanos (DIDH). Mientras el DIH hace alusión a la violación de las Convenciones de Viena y crímenes de guerra, en el otro caso se hace alusión a las violaciones al DIDH, entre las cuales se encuentran, a la luz de la Corte Constitucional, los crímenes de lesa humanidad. 
de víctima y al subsumir con él, el desplazamiento interno como parte de un universo más amplio de formas de victimización (Aparicio, 2012) ${ }^{29} \mathrm{De}$ este modo, los discursos y las prácticas de la justicia transicional fueron incorporadas por las organizaciones y colectivos, movilizando un nuevo lenguaje legal y resistiendo, paradójicamente, la Ley de Justicia y Paz.

Durante el desarrollo de esta investigación tuve la oportunidad de participar en algunas actividades, intervenciones públicas y encuentros desarrollados por el Movice y otras organizaciones gubernamentales y no gubernamentales en los que siempre se instaló parcial o totalmente la "Galería por la memoria" ${ }^{30}$ Por invitación de un miembro de Hijas e Hijos, asistí, en el año 2009, a una conmemoración en el municipio de Soacha, en solidaridad con las madres de los llamados "falsos positivos" de este municipio. Durante la jornada, miembros del Movice proyectaron el documental Falsos Positivos del periodista italiano Simone Bruno. Durante mi permanencia vi familias enteras, niños en bicicletas y triciclos, padres y madres que pasaban comiendo helado y zigzagueando alrededor de las fotos en retablos; otras personas se detenían a ver el documental, algunas pasaban de largo, y otros curiosos, muy pocos, preguntaban por los retratos y el sentido de la jornada.

Esta forma de memoria performativa ${ }^{31}$ intenta movilizar la memoria en los espacios públicos, articulando la dimensión política y la dimensión pedagógica que su despliegue conlleva en una sociedad entramada por la violencia permanente. Particularmente la dimensión política aspira, por un lado, a la verdad, la justicia y la democratización de la sociedad y, por otro, a que estos eventos no se repitan, de modo que la verdad y la memoria

29 En revisión de prensa se puede observar cómo el concepto de víctima empieza a ser usado de manera sistemática a partir del año 2000, incrementando de manera dramática para el año 2010 y cobijando distintas formas de victimización. Los efectos sociales y políticos de esta transformación del lenguaje están por ser estudiados para efectos del diagnóstico de las políticas públicas y su focalización. Otro elemento clave es que las víctimas pasaron a ser el objeto central de gobierno y la política pública, sustituyendo el enfoque previo en indígenas, afrodescendientes y desplazados.

30 Esta galería expone los retratos de personas retenidas, asesinadas o desaparecidas, cada una con los nombres de las personas fotografiadas. Generalmente se disponen en retablos en el piso o en carteleras sobre una pared.

31 Según Connerton (1989) la memoria social se puede encontrar en las conmemoraciones, pero aclara que las ceremonias conmemorativas solo existen si son performativas. La memoria performativa es altamente representacional y fundamentalmente corporal, un aspecto aún poco estudiado de la memoria. 
hagan parte fundamental de la sociedad, como lo menciona un miembro del movimiento: "una oportunidad para que las fuerzas sociales que han sido excluidas, perseguidas y estigmatizadas puedan participar de la vida pública" (Miembro del Movice, entrevista realizada el 8 de abril de 2009).

En este contexto, la "Galería por la Memoria" resulta un trabajo central en la producción de tecnologías de memoria del Movice (GMH, 2009). Esta forma de memoria contrasta con los objetivos del GMH, debido a que el Movice busca explícitamente, "no solo el derecho a la memoria", sino también la aplicación plena de la justicia, la verdad judicial y la reparación. De este modo, el Movice responde diferenciadamente a lo que el GMH y el CMPR han articulado desde la puesta en marcha de la Ley de Justicia y Paz. Por ejemplo, uno de los grandes desacuerdos entre el Movice y el GMH radica en el uso que se le otorga a la memoria histórica. Mientras que representantes del GMH buscaban recuperar la memoria de las víctimas en cualquier momento y en cualquiera de los casos emblemáticos estudiados -aunque en estricto sentido estos informes no recuperen la memoria histórica-, como forma de dar voz a las víctimas, el Movice privilegiaba la memoria como parte de una estrategia jurídica de "memoria histórica", como ellos también la han definido, que busca no solo el acompañamiento a las víctimas, sino promover dispositivos simbólicos para la no repetición de dichos actos de violencia. Otra diferencia entre ambas organizaciones se da en que, por una parte, el GMH privilegia el análisis multicausal de la violencia, en cambio el Movice ve al estado como un actor central en la generación de violencia. Estas dos perspectivas muestran los diferentes posicionamientos frente al pasado violento, sus causas y los usos de la memoria.

Ahora bien, si el GMH quería en este marco contribuir al esclarecimiento histórico, el Movice buscaba durante este periodo que la recuperación de la memoria sirviera para la reivindicación de las víctimas, el establecimiento de una comisión de la verdad y juzgar a los perpetradores. ${ }^{32}$ Es decir, el Movice buscaba que el trabajo de la memoria reivindicara y resignificara el sentido tradicional que se le ha dado a las víctimas y a las justificaciones sociales y estatales que se han dado tradicionalmente sobre estos crímenes. En ese sentido, la memoria del Movice también puede ser definida como

32 En la actualidad no es claro para mí si en el contexto de los actuales diálogos de paz, el Movice tenga otra posición al respecto. 
"memoria reivindicativa", en tanto busca ir más allá de la recuperación de la memoria de las víctimas para construir un mensaje que se fundamenta en el reconocimiento social y estatal de su victimización pero, fundamentalmente, con derechos sociales y políticos. ${ }^{33}$

En contraste con el GMH y CMPR, el Movice revela otro aspecto de los efectos de la apropiación de mecanismos y tecnologías de la memoria en Colombia. Si para el GMH, la verdad y la justicia hacen parte del método mismo de construcción de la memoria histórica, fundamentado en los métodos jurídicos, históricos, cartográficos, estadísticos y sociológicos, para ser incluidos en la narración histórica, para el Movice, verdad y justicia son el horizonte de su lucha para dejar de ser, como lo afirma uno de sus miembros, "objeto de ayuda humanitaria y convertirse en sujetos de derechos" (Miembro Movice, entrevista realizada el 8 de abril de 2009)

Se puede afirmar que las luchas de la memoria que discurren en estos espacios, se encuentran al mismo tiempo en una lucha por la legitimidad. Mientras que las iniciativas de memoria gubernamentales luchan por su propia legitimidad académica y/o política, las iniciativas de memorias no oficiales luchan por su propia legitimidad como organizaciones sociales, legitimidad que se verá materializada en la verdad histórica, la verdad jurídica y las garantías de sus derechos.

\section{Hijas e Hijos}

"Hijas e hijos somos todos" era la primera consigna que la organización cantaba y escribía en pancartas durante este período. Cada letra del slogan sin olvido era llevada por sus miembros en marchas, scratches y batucadas. Por medio de esta consigna invitaban a que todos los jóvenes de su generación se vieran a sí mismos como hijas e hijos de la violencia generalizada. "Hijos", como se le llama comúnmente, nace como respuesta a una violencia muy específica; la violencia ejercida contra miembros de la Unión Patriótica y líderes de la izquierda de mediados de los años 80 y 90 . Esta generación de

33 María Victoria Uribe ha interpretado la memoria del Movice como "memoria constituyente". Es decir, como una memoria que se proyecta sobre la realidad social, y que supera el estatismo de la memoria constituida, de una concepción de memoria archivada en los grupos y/o los individuos (Uribe, 2009, p.190). 
hijas e hijos que ahora están en sus veinte y treinta años de vida se unieron para compartir sus experiencias.

Esta organización se formó oficialmente el 8 de julio de 2006 como respuesta a la Ley de Justicia y Paz. En la inauguración, con la presencia de Antonia Segarra de la Asociación de la Plaza de Mayo de Argentina, el sociólogo Antonio Molado y otros, Hijas e Hijos, definieron dos parámetros muy importantes para esta organización: el carácter "cultural de la memoria" y su interpelación política en los ejercicios de memoria. ${ }^{34}$ Para algunos de los miembros de Hijas e Hijos este proyecto político significa continuar con los ideales de sus padres, pero por fuera de la cultura política tradicional colombiana. Así lo afirma uno de sus integrantes:

Nosotros no queremos replicar los errores de nuestros padres. Tampoco queremos replicar la estructura política colombiana. Es por eso que rechazamos las organizaciones verticales. Nuestros padres creían que por medio del sistema político podían hacer reformas soñadas. En cambio nosotros creemos que Colombia necesita un cambio, pero en su sistema político, es por eso que insistimos en intervenciones públicas, celebraciones regionales, encuentros académicos, conmemoraciones con charlas, exposiciones, videos, fotografías y batucadas (Miembro Hijas e Hijos. Entrevista realizada el 5 de junio de 2009).

Hijas e Hijos nació como una organización que hace explicita su marginación de la política tradicional y de los partidos políticos, argumentando que no confían en el estado, pero sí en las intervenciones públicas realizadas en las calles, en las plazas y en los pueblos. Por medio de estas iniciativas, la organización trató de mostrar que la memoria es un lugar de lucha por el significado del pasado, un terreno donde la definición de lo que es recordado y olvidado es una apuesta que está en juego, un lugar donde los actores sociales luchan por el monopolio de su propia representación.

34 La ley de Justicia y Paz cataliza la emergencia de Hijas e Hijos. Así lo expresa un miembro de esta organización en el discurso de inauguración: "Nosotros empezamos conociéndonos los unos a los otros en Argentina, Chile, Uruguay y en los Países Bajos. En esos momentos en que las conjeturas avivan los recuerdos, la Ley de Justicia y Paz nos ataca a nosotros como seres humanos y nos imposibilita quitarnos el velo para desmantelar las mentiras y nos hace caer en cuenta que la reconciliación nacional no puede ser impuesta por decreto" (Palabras de inauguración del evento). 
Las demandas de Hijas e Hijos contrastaban con el discurso público del CNRR y CMPR. Mientras los miembros de la CNRR afirmaban que "la mayoría de las víctimas colombianas son mujeres pobres que tienen el deseo de olvidar", los integrantes de Hijas e Hijos mostraban lo problemático de esta generalización. Para ellos, "ni perdón, ni olvido" constituía un elemento central a su visón de la memoria ${ }^{35}$, que buscaba, con el fortalecimiento de la verdad y la memoria, transformar la cultura política, en contraste con la postura del Movice, en la que era claro el deseo de alcanzar la justicia, o la de la CNRR, que trabajaba por la verdad en dos ámbitos: en versiones libres (audiencias que hacen parte de la Ley de Justicia y Paz) y en sus propios reportes de memoria histórica.

\section{La justicia transicional como nuevo horizonte de sentido para el estado y las organizaciones sociales}

Pero, icómo podemos interpretar la apropiación técnica, legal, discursiva y cultural de mecanismos de justicia transicional por parte de instituciones del estado y organizaciones sociales en Colombia durante los últimos años?, ¿de qué manera podemos dar sentido a la implementación de políticas, dispositivos transicionales y perspectivas de memoria en un contexto de conflicto sin transición?, ¿qué hace que el estado colombiano y las organizaciones sociales y de víctimas hayan movilizado con tanta fuerza (incluso sus más serios detractores) los mecanismos y conceptos de la justicia transicional, como si el lenguaje transformara la realidad con solo nombrarla?, ¿cuáles son los efectos socioculturales de esta transferencia y qué elementos aporta al desarrollo o no de transformaciones institucionales y sociales?

Las externalidades del derecho, o lo que aquí he llamado las consecuencias inesperadas de la Ley de Justicia y Paz, pueden dar luz sobre algunas de estas preguntas. Estas consecuencias se manifiestan en el despliegue de nuevas prácticas y discursos culturales, políticos e institucionales. Entre estos emergen nuevos dispositivos de memoria, como los informes del Grupo, su uso y apropiación por jueces y víctimas, la lucha del GMH al interior

35 Es probable que esta visión ya no sea compartida por todos. Al parecer, en la actualidad el movimiento cuenta con diferentes vertientes y perspectivas. 
las instituciones públicas por ganar autonomía y legitimidad, la existencia del grupo mismo y su posterior transformación en el Centro Nacional de Memoria Histórica. Por otra parte, vemos sus efectos en la apropiación y resistencia de la justicia transicional y de la memoria como problema político, responsabilidad del estado, objeto de aprendizaje y forma de lucha por la ciudadanía. Igualmente, promueve la reorganización del movimiento social, su visibilización y re-significación. Por último, la emergencia de nuevos debates sobre el museo, el memorial, el archivo y las políticas públicas de la memoria. Estos efectos pueden ser entendidos como un proceso de transformación de la cultura política, y como expresión de unas nuevas políticas de la memoria en Colombia.

La relación entre los hechos ocurridos y la forma como estos son apropiados por los sobrevivientes ha sido un tema central en los debates sobre la memoria, sobre todo en lo referente a la relación entre esta y la verdad, más no en relación con el sentido de justicia. Este hecho se hace más problemático cuando dichas experiencias trascienden a las víctimas, y se proyectan en el espacio y el tiempo por medio de diferentes formas de representación material o inmaterial cuyo sentido es transformado por medio de la transmisión y apropiación generacional. En el caso colombiano, el problema de la trasmisión generacional encarna una dimensión específica en tanto que existe, por un lado, la transmisión generacional de la memoria del pasado violento y, por el otro, la continuación de la violencia en sus variadas manifestaciones. ¿Cómo se entremezcla, en este caso, la transmisión de la memoria del conflicto y la permanente producción de violencia, sin que, como en Alemania, España o Argentina, sean las generaciones siguientes quienes tramitan las experiencias de las generaciones pasadas, sino que las violencias del pasado y el presente se yuxtaponen y entremezclan sin límites claros y son incluso difíciles de delimitar por el investigador?

Lo anterior plantea un tema analítico y metodológico central para el estudio de la memoria y la justicia transicional: la transmisión de las memorias entre quienes vivieron una experiencia y quienes no la vivieron, la reinterpretación que hacen de tales hechos y el papel que esto puede tener para el futuro. De este modo, podemos decir que las diferentes concepciones de memoria desarrolladas por las organizaciones sociales e instituciones públicas aquí elucidadas, dan sentidos y usos a la memoria que no necesariamente articulan las mismas temporalidades y nociones 
de justicia. Es este sentido es que la justicia transicional se convierte en un problema etnográfico, político y cultural muy relevante.

Este problema de la temporalidad es importante para pensar no solo en el papel de la memoria en el posconflicto, sino en una apuesta que integre el debate de la memoria en la política y la retire del campo de la violencia y la confrontación. Los conflictos trascienden las generaciones y la manera como se enfrentan depende la reconstrucción futura.

De este modo, puede verse cómo los mecanismos transicionales no solo han sido apropiados como instrumentos de fin del conflicto y construcción de paz, ${ }^{36}$ sino que nos remiten a plantear problemas asociados con la apropiación creativa de herramientas del derecho internacional con diferentes fines y propósitos. También, claro está, nos permite dilucidar cómo estos conceptos, mecanismos e instrumentos despolitizan la intervención del estado (Ferguson 1994) y cooptan las palabras, la experiencia y las prácticas de los sujetos. Sin embargo, la apuesta por el vocabulario (transición, posconflicto, fin del conflicto, memoria histórica, deber de memoria, justicia, verdad, reparación), las medidas, las prácticas y los mecanismos transicionales e instituciones de posconflicto, también pueden entenderse como una manera de desbloquear la imaginación política, después de la crisis institucional producida por el recrudecimiento de la violencia a finales de los 90, y la negación del conflicto y las víctimas durante el periodo inmediatamente posterior. Igualmente, se puede afirmar que la justicia transicional funcionó como un punto de inflexión para relegitimar al estado, sin que este tuviera que afrontar los problemas estructurales asociados a las causas del conflicto por medio de un discurso de derechos que, si bien no ha tenido efectos materiales duraderos, sí ha pluralizado la interpretación de la violencia, alterando algunas técnicas y formas de gobierno en un contexto donde el discurso público oscilaba entre la negación de las causas del conflicto, y el despliegue de un nuevo lenguaje, y con él, todo un nuevo horizonte de sentido. ${ }^{37}$

36 La literatura sobre construcción de paz es inmensa. Los procesos de paz, las organizaciones sociales y las instituciones públicas han elaborado múltiples iniciativas de construcción de paz. Esto se constituye como un espacio para ser estudiado por los antropólogos.

37 Este proceso encuentra similitudes con el reconocimiento de los derechos civiles, políticos y culturales en 1991, reconociendo, entre otras, la victimización histórica de indígenas y afrocolombianos a través del marco interpretativo del multiculturalismo. Ante la crisis institucional de la década de los 80 , se incorpora el constitucionalismo en boga, no centrado en las causas de la violencia en 
De esta lectura también podemos destacar otros elementos importantes: por un lado, la emergencia de distintas formas de concebir la memoria, e indicios sobre formas emergentes de proliferación y jerarquización. Como vimos, el GMH ha diseminado con éxito el concepto de "memoria históri$\mathrm{ca}^{\prime \prime}$ al punto de convertirse en el concepto de memoria que ha terminado colonizando la esfera pública y de acción del trabajo sobre la memoria institucional y oficial, impactando las formas de memoria de grupos, organizaciones y comunidades. Por otra parte, está la "memoria democrática" movilizada por el CMPR, la cual guarda algunos elementos comunes con el concepto de "interpelación de la memoria" articulado por Hijas e Hijos. Estas concepciones de la memoria debaten el contenido político de la misma y su papel transformador en la sociedad. También discuten críticamente el proceso mismo de construcción histórica institucional, visibilizando los procesos sociales de lucha por la democracia. Al contrario, la "memoria histórica", por su misma delimitación encuentra su carácter político más en sus posturas metodológicas y teóricas. Por último está la memoria como forma de reivindicación política y legal del Movice, que destaca el carácter de dignificación que tiene la memoria para las víctimas, y su papel en la consecución de la verdad y la justicia.

Estas concepciones de memoria no son simétricas ni poseen las mismas condiciones materiales e ideológicas. La "memoria histórica" ha encontrado un terreno más fértil para su desarrollo, debido a que la perspectiva académica la blinda del problema ideológico y le otorga más o menos legitimidad. ${ }^{38}$ Las otras perspectivas abordan por sus propias características el

Colombia, sino en el reconocimiento de derechos de primera, segunda y tercera generación. Los antropólogos tomarían estos últimos para hablar y crear el "estado multicultural". Sin embargo, los derechos políticos y de ciudadanía, así como los derechos económicos y culturales, sirvieron para que toda una generación urbana reconceptualizara la ciudadanía, los derechos y la democracia. De este modo, comunidades, organizaciones e individuos, así como el mismo Estado entraron en un proceso de tránsito institucional en el que se dieron pequeñas aperturas democráticas que no promovieron cambios estructurales y que fueron lo suficientemente eficaces para cooptar la movilización social (Corte Constitucional, defensoría del pueblo, acción de tutela etc.). De este modo, la apertura democrática de 1991 prevé los retos que la transición política tiene hoy, no solo como fin del conflicto, sino con la real ampliación y profundización de la equidad y la democracia en Colombia.

38 Si bien la "memoria histórica" concibe la necesidad de rescatar las memorias desde el punto de vista de las víctimas y busca que esta memoria sea construida desde las múltiples voces y experiencias de quienes vivieron los acontecimientos, la memoria histórica en Colombia enfatiza en su carácter académico y experto, restringiendo discusiones políticas y morales. Por otra parte carece de una reflexión sobre la apuesta de futuro que el trabajo del GMH está haciendo en el presente (o por lo menos no es público). 
problema político e ideológico, incorporando de una vez por todas dentro del debate las elecciones que es necesario hacer sobre el pasado; sin embargo, sus efectos siguen siendo marginales.

Por último, este análisis plantea al menos dos preguntas en relación con el estado y la justicia transicional. Primero, incorpora la pregunta sobre el carácter hegemónico del estado en la producción de sentidos sociales. Si bien este artículo no defiende el determinismo legal, ni niega el carácter creativo de algunas instituciones y de lucha de las organizaciones sociales, sí se pregunta por la capacidad de la política pública de producir sentidos y significados. Después de años de lucha de las organizaciones sociales por reivindicar la memoria histórica de las víctimas, el estado, a través de la Ley de Justicia y Paz, apropia el concepto y lo disemina por medio de mecanismos institucionales, abriendo, sin esperarlo, un espacio para que el pasado y la historia fueran un problema de debate público.

A su vez, plantea la pregunta sobre el alcance de los debates relacionados con la memoria para transformar las interpretaciones tradicionales del conflicto y la democracia en Colombia. ¿Será que los debates sobre la memoria, sus usos y contenidos, lograrán que otras formas de registro cultural, como la conmemoración y el ritual de los grupos y organizaciones, sean reconocidos por las instituciones y la sociedad en su conjunto, constituyendo así una historia social y política incluyente, que aleje a la violencia de los terrenos de la diversidad, la alteridad y la diferencia?

\section{Referencias}

Abrams, P. (1988). Notes on the Difficulty of Studying the State. Journal of Historical Sociology. 1 (1), pp. 58-89.

Abu-Lughod, L. (2011). The Active Social Life of "Muslim Women's Rights". En

D. L. Hodgson (Ed.), Gender and Culture at the Limit of Rights. (pp. 101-119). Philadelphia: University of Pennsylvania Press.

Aguilar, P. (2008). Políticas de la memoria y memorias de la política. Madrid: Alianza Editorial, S.A.

Aguilar, P., \& Hite, K. (2004). Historical Memory and Authoritarian Legacies in Processes of Political Change: Spain and Chile in Comparative Perspective. En 
P. Cesarini \& K. Hite (Eds.), Authoritarian Legacies and Good Democracies, Notre Dame: University of Notre Dame.

Aguilar, P. (1999). Chapter 5: Agents of memory: Spanish Civil War veterans and disabled soldiers. En J. Winter \& E. Sivan (eds.), War and Remembrance in the Twentieth Century. (pp. 84-103), Cambridge: CUP.

Allier, E. (2010). Batallas por la memoria. Los usos politicos del pasado reciente en Uruguay, México: Trilce-UNAM.

Aparicio, J. R. (2005). Intervenciones etnográficas a propósito del sujeto desplazado: estrategias para (des)movilizar una política de la representación. Revista Colombiana de Antropología, 41, pp. 135-169.

Assmann, A. (2011). Canon and Archive. En J. K. Olick., et al. (eds.). The Collective Memory Reader. (97-107). New York: Oxford University Press.

Barclay, S. (2011). Two spinning wheels: Studying Law and Social Movements. Studies in Law, Politics and Society, 54, pp. 1-16.

Calveiro, P. (2006). Los usos políticos de la memoria. En G. Caetano. Sujetos sociales y nuevas formas de protesta en la historia reciente de América Latina. (pp. 360-382),

Buenos Aires: Consejo Latinoamericano de Ciencias Sociales - Clacso.

Connerton, P. (1989). How Societies Remember, Cambridge: Cambridge University Press.

Fassin, D., E Rechtman, R. (2009). The Empire of Trauma: An Inquiry into the Condition of Victimhood, Princeton: Princeton University Press.

Feldman, A. (2003). Political Terror and the Technologies of Memory: Excuse, Sacrifice, Commodification, and Actuarial Moralities. Radical History Review, 85(4), pp. 58-73.

Ferguson, J. (1994). The anti-politics machine: "development," depoliticization, and bureaucratic power in Lesotho. Cambridge: Cambridge University Press.

Hinton, A. (2010). Transitional Justice: Global mechanisms and Local Realities After Genocide and Mass Violence, New Brunswick, N.J.: Rutgers University Press.

Jaramillo, J. (2011). Expertos y Comisiones de estudio sobre la violencia en Colombia. Estudios Políticos, (39), pp. 231-258.

Li, T. (2007). The will to improve: governmentality, development, and the practice of politics, Durham: Duke University Press.

McCann, M.W. (1994). Rights at work: Pay equity reform and the politics of legal mobilization, Chicago: Chicago University Press.

Martínez, C. (2012). Memorialización y Politicas Públicas de la Memoria en Bogotá: Centro del Bicentenario Memoria, Paz y Reconciliación. (Tesis pregrado, Pontificia Universidad Javeriana, Bogotá). 
Mannheim, K. (1952). Essays on the sociology of knowledge, London: Routledge E K. Paul.

Merton, R. (1936). The unanticipated consequences of purposive social consequences. American Sociological Review 1(6), pp. 894-904.

Rosenberg, G. (2008). The hollow hope: Can courts bring about social change? Chicago: Chicago University Press.

Sieder, R. (2002). Políticas de guerra, paz y memoria en América Central. Las políticas hacia el pasado. Juicios, depuraciones, perdón y olvido en las nuevas democracias. En; A. Barahona, Brito, P. Aguilar Fernández \& C. González Enríquez (eds.) Las políticas del pasado. Juicios, depuraciones, perdón y olvido. (pp. 247-287), Madrid: Istmo.

Sturken, M. (1997). Tangled Memories the Vietnam War, the AIDS Epidemic, and the Politics of Remembering, Berkeley: University of California Press.

Trouillot, M. R. (1995). Silencing the Past: Power and the Production of History, Boston: Beacon Press.

Uprimny, R. (2008). ¿Justicia transicional sin transición?: Verdad, justicia y reparación para Colombia, Bogotá: Centro de Estudios de Derecho, Justicia y Sociedad.

Uribe, M.V. (2009). "Iniciativas no oficiales: un repertorio de memorias vivas". En M. Briceño-Donn, F. Reátegui, M. C. Rivera, y C. Uprimny (eds.). Recordar en conflicto: iniciativas no oficiales de memoria en Colombia, Bogotá, Centro Internacional para la Justicia Transicional (pp. 43-69), Bogotá: Centro Internacional para la Justicia Transicional - ICTJ.

Vinyes, R. (2009). La memoria como política pública. En J. Guixé, E M. Iniesta, (Ed.), Políticas Públicas de la Memoria: I Coloquio Internacional Memorial Democràtic. (pp. 19-32). Leida: Editorial Milenio.

Vinyes, R. (2004). Un futuro para el pasado. Proyectos de creación del Memorial Democrático. [Versión En línea]. Recuperado de http://www.londres38.cl/1934/ articles-83853_recurso_1.pdf, Barcelona, Universidad Autónoma de Barcelona Young, J. (2010). The Texture of Memory: Holocaust Memorials in History. En A. Erll \& A. Nümming (Eds.), Companion to Cultural Memory Studies. (pp. 357-365), Berlin \& New York: Walter de Gruyer.

Young, J. (1992). The Counter-Monument: Memory against Itself in Germany Today, Critical Inquiry 18(Winter), pp. 267-96.

Wilson, R. (2001). The Politics of Truth and Reconciliation in South Africa, Cambridge: Cambridge University Press. 